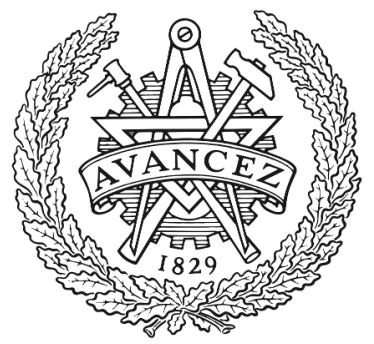

CHALMERS

UNIVERSITY OF TECHNOLOGY

\title{
Improved content mastery and written communication through a lab-report assignment with peer review: an example from a quantum engineering
}

Downloaded from: https://research.chalmers.se, 2023-04-26 13:34 UTC

Citation for the original published paper (version of record):

Bylander, J., Gustafsson, M. (2021). Improved content mastery and written communication through a lab-report assignment with peer review: an example from a quantum engineering course. European Journal of Physics, 42(2). http://dx.doi.org/10.1088/1361-6404/abcb57

N.B. When citing this work, cite the original published paper. 


\title{
Improved content mastery and written communication through a lab-report assignment with peer review: an example from a quantum engineering course
}

\author{
Jonas Bylander $^{1, *}(\mathbb{C})$ and Magnus Gustafsson ${ }^{2}[$ \\ 1 Department of Microtechnology and Nanoscience, Chalmers University of \\ Technology, SE-412 96 Gothenburg, Sweden \\ 2 Department of Communication and Learning in Science, Chalmers University of \\ Technology, SE-412 96 Gothenburg, Sweden \\ E-mail: jonas.bylander@chalmers.se and magusta@chalmers.se
}

Received 22 July 2020, revised 5 November 2020

Accepted for publication 17 November 2020

Published 8 February 2021

\begin{abstract}
The promotion of high-quality written communication in the disciplines is an important learning outcome in higher education. Given the time invested by students and teachers alike, it is crucial that writing assignments also promote engagement and content learning. But is it worth the time for university teachers to invest in such 'writing-to-learn' activityes? We find that it can be, and present an improved design for an experimental lab-report writing assignment in an English medium instruction environment, where English is an additional language. Our context is assignment development for formative assessment in master's-level physics, but the method is broadly applicable within the science-technology-engineering-math disciplines. Our first experience with the assignment resulted in substandard lab reports, suggesting insufficient subject understanding and prompting this assignment design. We therefore focused on communicating the alignment of aims, learning objectives, instruction, assessment criteria, and feedback design, and developed simplified rubrics facilitating assessment fairness and efficiency. The revised assignment enhanced the learning of the subject matter and the writing quality over the four years of the study, indicated by clearly improved reports and relevant peer feedback comments. The learning activity also had an observable but less distinct effect on the students' exam performance.
\end{abstract}

${ }^{*}$ Author to whom any correspondence should be addressed.

Original content from this work may be used under the terms of the Creative Commons Attribution 4.0 licence. Any further distribution of this work must maintain attribution to the author(s) and the title of the work, journal citation and DOI. 
Keywords: lab report, collaborative writing, peer learning, writing-to-learn and learning-to-write, discipline-specific writing, experimental quantum physics, formative assessment

S] Supplementary material for this article is available online

(Some figures may appear in colour only in the online journal)

\section{Introduction}

Many educators would agree that writing is often an integral part of our assessment methods and a tool in many of our teaching and learning activities. At the same time, there is a long tradition of complaint about student writing, and literature on how to address these problems [1-3]. For the reader oriented toward physics education research (PER), the concern with writing has been addressed over the years at a generic level for instance by Becker [4] and by Mermin [5] (also note Kalman and Kalman [6] in response to Becker). In more recent years, Franklin and Hermsen [7] have provided an excellent review on this writing studies topic for the physics-oriented readership.

The conceptualization of problems with writing was initially viewed largely as a deficiency issue (see Lerner [8] on the history and development of writing labs in US higher education), and gave rise to efforts with a focus on 'learning to write' (LTW). This emphasis on LTW in design and assessment is justifiable since it is important that students acquire the written discourse appropriate to their specific sub-field of study and scientific level. However, it seems possible to also make sure a writing assignment promotes reflection and critical thinking about disciplinary content and methodological knowledge [9-12]. Using writing to promote conceptual understanding appears justified also since recent research on undergraduate physics lab teaching showed that the labs did not necessarily contribute to student learning of the concepts covered in lectures [13-18], that labs focusing on conceptual understanding led to less expert-like thinking among students [19] (i.e. contrary to the goals of the lab modules), and that feedback was not always acted on [20]. It therefore seems a priority to develop methods for enhancing students' content mastery through labs.

Consequently, the frustration with the deficiency approach eventually gave rise to what might be called a 'writing-to-learn' school (WTL). Where LTW focuses on the disciplinary academic writing expectations, employs the genres that are frequent in the discipline, and promotes students' use of professional communication, WTL has a stronger focus on the learning process and on using writing activities that prompt reflection and engagement with conceptual as well as procedural learning. WTL and LTW activities sit on a continuum and are in no way mutually exclusive; most writing activities will have degrees of both dimensions. One way of conceptualising that continuum is to look at how a writing-across-the-curriculum program (WAC) designs activities and assignments across a spectrum from possibly informal in-class WTL-activities like reflective journaling perhaps, to longer-duration and more formal assignments like drafting a lab or a project report that meets disciplinary standards. The disciplinary writing is often referred to also as 'writing-in-the-disciplines' (WID) and overlaps in significant ways with a more recent label for writing activity designs that focuses on 'writingas-professionalization' (WAP, cf Hoehn and Lewandowski [12]). We also recommend the avid reader to consider the accessible definitions of the concepts on this continuum as provided by the WAC Clearinghouse [21]. 
WTL appears to have grown out of faculty preferences rather than evidence-based studies of student learning and it was critiqued accordingly in the 90s by Ackerman [22]. For the physicsoriented dimension of this critique, we also refer readers to Kalman and Kalman [6] and to a 2006 thesis by Demaree [23] on the topic of writing to learn in physics. Despite Demaree's study and the many ways that writing is used in physics education, at different levels [23-27], most of the physics higher education literature on lab reports we have isolated appears to focus less on the WTL dimension and more on LTW. For example, Kiani and Menke [28] studied writing development in an upper division physics laboratory course and found that it improved with feedback but they did not mention effects on conceptual knowledge or performance. Similarly, Kane and Browne [29] studied teacher feedback on lab report writing in undergraduate optics and found an improved learning environment but did not study content understanding or go beyond conversations with students to quantify this learning enhancement. Ellingsen and Støvneng [30], finally, also studied physics lab-report writing in a well-designed study. They account for an effective change in feedback and assessment design for undergraduate courses and one graduate course and found significant improvement of lab reports as well as some correlation with course grades, but their study does not include any high-resolution data on students' content knowledge as such.

The writing studies discipline has also pursued the challenge of determining the impact on learning in many ways and disciplines, and in one study of relevance to STEM fields, Carter, Ferzli, and Wiebe [31] conducted a study of lab report writing in biology. They define the lab report as an apprenticeship genre and as such it functions both as WTL and LTW (and WAP). It is used for promoting learning of a delimited area of disciplinary content while it also allows practicing writing in ways that meet the expectations of the discipline. What Carter and colleagues wanted to study was how students experienced the laboratory report WTL task, and the interview data they collected generated six ways in which students claimed to have learned from the assignment (p 286): learning (1) by writing, (2) by writing the genre, (3) by enhancing learning behaviors, (4) by using reports for future reference, (5) in other contexts, and (6) in contrast to other modes of learning. What their analysis of the student experience seems to suggest is that WTL is more than just a faculty preference and actually something echoed among students in their study when interviewed about a well-designed WTL task. A subsequent review of STEM-related publications on WTL similarly suggests support for the WTL hypothesis and offers a WTL model for STEM [10]. For the more specific scope of our paper, the excellent framework introduced recently by Hoehn and Lewandowski includes WTL among the goals for writing in physics lab classes. [12]

While Carter et al show that students appear to experience the lab report assignment as a learning activity that also promotes content learning, their study does not report on if, or to what extent, student content learning performance actually improved accordingly. Similarly, Demaree's review and her own quasi-longitudinal study find only limited support for the WTL hypothesis. For many WTL tasks studied across levels and disciplines, when enhanced learning is observed, it seems to be connected to tasks that involve reflection and metacognition [32-35]. This emphasis on reflection has also been noted in the PER-community as exemplified by Stanley and Lewandowski [36] in their recommendations for working with notebooks in advanced lab courses (see also Dounas-Frazer and Reinholz [37] and Lasry, Charles, and Whittaker [38]).

It is possibly this connection to reflection that provides a strong link between studies of WTL impact and studies of feedback on writing. Hattie and Timperley [39] showed that feedback is most powerful when it helps move the student from mere task correctness to processing and self-regulation. Nicol [40], and more recently Boud and Molloy [41], offer elaboration and problematisation on good designs for written feedback, and recommend that teachers ensure 
that it, above all, is expressed in learner actions, adapted to student needs, and perceived as nonjudgmental. Nicol [42] also emphasises the teacher-student dialogue for bringing about the crucial active student engagement with the task goals, criteria, and exemplars; he argues that this may be done, without increasing teacher workload, even with large student numbers, by using student peers, collaborative assignments, and exposing students to others' dialogues. While the design and use of formative assessment may be challenging ( $\mathrm{cf}$ the review by Bennett [43] for a good account of school-level formative assessment), we do believe informed formative assessment designs help promote WTL impact and guide writing development through the reflection it generates and the self-regulation it prompts.

In this paper, we report on the design and outcome of a writing assignment connected to a laboratory experiment. First of all, it must be said that our paper does not present a full-scale writing intervention research study [44] but reports on a small-scale action research study. In other words, we do not have the research study setup that Ackerman called for [22]. Nor do we have sufficient replicable, aggregable, and data-supported material that Haswell [45] requires for high quality writing studies work. However, we hope our course context and action research conditions account for the most obvious limitations in the paper. Despite these limitations, our design follows the recommendations for engineering communication education by Paretti et al [9] as well as the model provided by Reynolds et al [10], but we specifically add to the study by Carter and co-authors by also attempting to account for the impact of WTL on conceptual understanding. What interests us is not only trying to study the impact of WTL activities, but making the most of the overlapping WTL-LTW spheres of writing instruction as we study the impact on both LTW and WTL over four iterations of a course and an assignment. Our results show that this method is effective, compared to a baseline assessment of lab reports without collaborative writing, feedback, peer discussion, and revision.

The assignment design project we report on here is our attempt to analyze the design and impact of a lab experiment report assignment in terms of its effect on writing quality as well as conceptual understanding. Here, we present our new design of teaching and learning activities, according to constructive alignment principles [46] including formative assessment via peer and teacher feedback for the revision of the reports. Our context is an advanced-level physics course with a state-of-the-art laboratory experiment and subsequent report writing (cf references [47] and [48]). The course is offered in an English medium instruction environment and students are multilingual with English as an additional language. Author 1 taught the course for the first time in 2013 ('year 1'), and while a few of the lab reports were of reasonable quality, several were poor, suggesting unsatisfactory subject understanding and writing skills among students. Better-written reports would benefit the students through more effective formative assessment $[42,49,50]$ and have the added benefit of saving teacher time when grading and giving feedback. The method described in this paper-writing assignment with criterionbased peer and instructor feedback and revision - is aimed at enhancing conceptual learning and experimental awareness through an experiment and the subsequent lab-report assignment for the MSc-level. Peer response and writing process designs have been used in science education, see e.g. references [51] and [52], and peer instruction is studied in the PER-context $[53,54]$, but we believe we offer a closer analysis of its impact and a transferable rationale for the design.

\section{Course description and teaching approach}

The objective of the course quantum informatics and quantum optics is to enable student learning about semi-classical and quantum models for the interaction of matter and radiation, and how photons and natural and artificial atoms can be used to represent and process 
quantum information. To scaffold learning and enhance student learning of quantum engineering through experimental experience, the course also includes a laboratory exercise including a report-writing assignment.

The lab experiment focuses student learning on two of the major intended learning outcomes (ILOs) of the course:

- Explain the Jaynes-Cummings model for how matter and radiation interact at the quantum level

- Use the Bloch equations to describe a two-state system's dissipative dynamics

The aims for the lab itself are summarized as follows:

(a) Help students concretize some central concepts in an otherwise theory-heavy course

(b) Teach students experimental skills relevant for a quantum engineer

(c) Offer students an opportunity to improve their skills in communicating and reporting on a scientific/technical topic

During the lab session, the students first observe an experiment in our research laboratory, and then do hands-on work using our equipment and a microchip made in our group.

In preparation for the lab session, the physics of the model system under study [55-57] is covered during lectures and in a homework assignment. Furthermore, a 45 min lecture introduces the experimental techniques to be used in the lab to test the physical model. A lab memo is handed out several days prior to the lab [see memo in section A of the supplementary material (https://stacks.iop.org/EJP/42/025701/mmedia)]. In summary, it offers an introduction emphasising the use of research equipment and samples, and the learning of experimental and communication skills. It repeats the learning outcomes and provides study questions for preparation as well as instructions for the lab report, including assessment design.

\section{Lab work and report assignment}

Each lab session lasts 3-4 h and accommodates about four students who work in pairs; the students were tutored by author 1 in years $1-2$, and by a graduate teaching assistant in years 3-4. The session consists of,

(a) A short introduction, including a repetition of the ILOs

(b) Demonstration of the lab equipment and measurement techniques

(c) The different measurement tasks for the different student pairs

(d) Discussion of the results.

Experimental data is subsequently sent to the students for analysis.

At the end of the lab, the students are instructed to work on their reports in teacher-assigned mixed-background pairs (first language and undergraduate major), whenever possible. In order to help them choose an appropriate level of background explanation and detail in their texts, the intended reader is identified as another student of the course, who has not done the lab. The students are informed that the reports will be marked according to criteria and rubrics, which are communicated to them (see the next section on assessment).

\section{Assessment}

Assessment of the reports is done in two steps. A first version of the reports is due one week after the lab session, so as to keep the work focused and to finish the following review process 
well before the course exam. As the examiner, author 1 reads all the reports, without grading them, but instead provides collective feedback on commonly encountered issues with, e.g., apparent content misunderstanding, data analysis, style and level of explanation or background information, writing, and layout. Each student writing-pair is then assigned to review the report of one other writing-pair and discuss their comments in a meeting. To the extent possible, these two pairs are chosen such that they have attended different lab sessions, and have also been assigned different measurement tasks, so that the contents of their reports will vary. The two pairs are expected to meet and discuss the qualities of their respective reports. They receive no specific guidelines for this step in the process other than the criteria and rubrics. The respective pairs then submit, within one week, three items to promote engagement with the assignment and the peer review process:

- A second (final) version of the report

- The received peer comments

- A reflection on those comments and the changes implemented

The teacher assesses the second version of the reports according to the rubrics, assigns a mark that accounts for $25 \%$ of the course grade, and provides individual feedback to writing groups on request.

In terms of effective design, it is particularly important to strive for clear communication of concrete ILOs and assessment based on simplified and adapted criteria. In the first year, these objective-related assessment criteria were not explicitly communicated to the students, with the purpose that the students themselves should figure out how to address the learning objectives instead of merely following a checklist, which might not be conducive to reflective learning. However, in years $2-4$, the students were informed that the reports would be graded according to an abbreviated version of the extensive local criteria [58] used for the assessment of BSc theses at the university. We developed the articulation of criteria with a focus on the rubrics - 'CHI,' encompassing content and understanding (weight 50\%), holistic impression (20\%), and information structure (30\%) - that elaborated on grading criteria applicable for technical/scientific writing (see section B of the supplementary material https://stacks.iop.org/EJP/42/025701/mmedia). These rubrics are intended to facilitate grading consistency and fairness, reduce teacher workload during assessment, and help guide student work -in particular student peer review and reflection. The students were also informed that their quality of and response to peer feedback would be taken into account.

\section{Feedback to students}

In year 1 the students were assessed directly on their reports. The following years, feedback from the teacher to all the students collectively, and between the teacher-generated peer pairs, helped improve nearly all of the second-version reports compared to the first-versions. This approach with mandatory peer review and revision implicitly addresses the seven points of effective feedback suggested by Nicol and Macfarlane-Dick: [50]

(a) Facilitate the development of self-assessment (reflection) in learning.

(b) Encourage teacher and peer dialogue around learning.

(c) Help clarify what good performance is (goals, criteria, expected standards).

(d) Provide opportunities to close the gap between current and desired performance.

(e) Deliver high quality information to students about their learning

(f) Encourage positive motivational beliefs and self-esteem. 
(g) Provide information to teachers that can be used to help shape the teaching.

The writing process and the peer review also facilitate active student engagement with the task as well as the process. The rubrics relate the writing activity to clear goals, and peer feedback can build a shared commitment and help bring the students to reflect on the writing process, leading to self-regulation, development of internal (reflective) feedback, and self-assessment.

With the revision of the assignment, the collective teacher feedback has been more or less evenly distributed between LTW and WTL comments. In year 3, the list of general comments ranged from an LTW comment like 'You may very well use the active voice when you write' to more demanding WTL reminders like 'You can interpret your results using the dispersive Jaynes-Cummings Hamiltonian (read-out, spectroscopy; which states are you using in the experiment?), and Bloch equations (decay, saturation of populations).' In year 4, the teacher commentary remained largely balanced on the LTW-WTL axis, but was more detailed. A detailed comment that concerns both content understanding and genre expectations is exemplified in the following:

'The time scale for the decay of the Ramsey fringes is commonly denoted $T_{2}^{*}$ ('T-2-star'). It is due to a combination of $T_{1}$ energy relaxation and pure dephasing with a time constant $T_{\varphi}^{*}$. In a widely applicable model one adds the rates of relaxation along $x, y$, and $z$, to obtain $1 / T_{2}^{*}=1 / 2 T_{1}+1 / T_{\varphi}^{*}$.

On the one hand, the teacher formulates the expected performance, delivers high quality information, and helps students close gaps between their performance and the expected one. On the other hand, the entire feedback design, including student peer feedback, is also intended to promote dialogue as well as provide information to the team of teachers about the teaching.

\section{Results and analysis}

The course evaluation system at the university provides the most basic evaluation of the course development process. The standard set of questions scales from 1-5, and the overall comment for the course increased from 3.4 in year 1 to 3.8 in year 4 with a higher value for year 2 at 4.0. More importantly, perhaps, students indicate a higher workload from year 2 and onward but still find the course 'better' than the first group of students did in year 1 .

However, since course evaluation data are questionable for assessing course design simply by being too general and rarely sufficiently representative, we needed additional ways to try to assess the impact of our design. Furthermore, course evaluation data refers to the entire course, whereas we have focused this study on the scaffolding of the laboratory experiment and report assignment, which accounted for $25 \%$ of the grade.

As one way to get higher resolution data, we look at the performance as indicated via grades. The data in figure 1 show the lab-report marks and course grades (median and standard deviation) among the students that completed the course. The number of students each year is also indicated. In year 1, there were considerable problems with content understanding in the student group; moreover, the students' writing ability varied significantly. There were 19 individual reports and 11 of these scored below the pass level $60 \%$ for content understanding. The writing varied more but 6 students failed to reach the pass level. However, over the course of the four years of the study, the lab-report marks clearly show a monotonic increase and a diminishing spread. The most prominent improvement is that from year 1 to year 2, which we attribute in large part to the revised assignment.

Unlike the first-year experience, no reports in the years 2-4, even in their first versions, had severe problems of the kind observed for reports in the first year. Nevertheless, the 


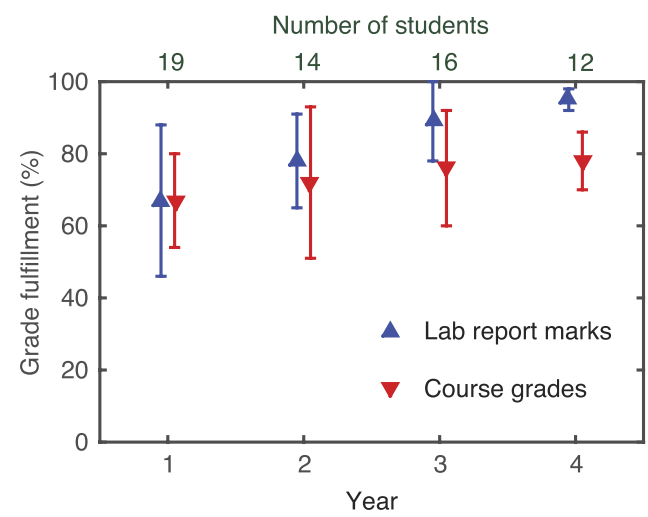

Figure 1. Median lab-report marks and course grades obtained by the students in four iterations of the course; vertical bars indicate the spreads among the students' results (1 standard deviation).

revisions prompted by the teacher feedback, and that of the student peers, have led to significant improvements between the first- and second-version reports. The less good reports seem to have benefitted the most by the revision, but even the better reports were improved.

The course grades show the same increasing trend, although to a smaller extent, and likewise a diminishing spread (except for the smaller spread in year 1). Seeing that the exam tests all the learning outcomes of the course, it is reasonable that there seems to be a ceiling effect for the extent to which the lab report ( $25 \%$ of the grade) can be seen to promote exam performance on the entire course.

A second dimension to investigate in this design is the student activity and performance as peer reviewers. Most student pairs were thorough in their peer-review work, often providing one full page or more of comments, and they all tended to comment in great detail. Given that the data set is small —a total of 13 documented reports with peer review over the year 3 and 4 runs of the course-we have to be cautious in our analysis and interpretation, but some observations can be made. On the one hand, the feedback students provided each other appears to confirm some of the peer response literature findings $[59,60]$ in that there are some predictable surface-oriented comments on grammar, sentence structure, referencing mechanics, and style (cf 'later order concerns' [61]). However, there are also many comments oriented more directly at content understanding or engaging with the content. We have categorised such comments as WTL comments.

In the analysis of the student peer feedback comments, we did not use any of the reported and previously used coding schemes, e.g. references [60, 62, 63]. Instead, we focused our attention on whether a comment was oriented toward issues of presentation, like language, style, and structure, which would make it an LTW comment, or toward the understanding of content, which would make it a WTL comment. Granted that there is some overlap between these two broad categories, where comments about audience adaptation of the text or argumentation would be examples, we found the comments distributed toward the understanding of content.

In the 13 reports, a total of 192 comments were made: 115 are content-oriented while 77 focus on language, style, and structure (see figure 2).

While there were of course also regular proof-reading comments, two representative LTWoriented comments would be the following advice about figures and paragraphing: 


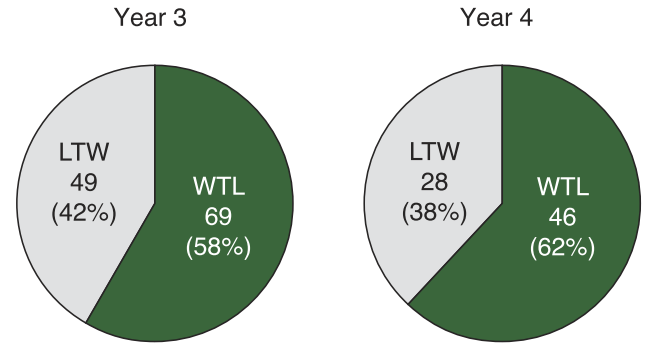

Figure 2. Distribution of peer feedback comments (years 3-4): there were 7 reports in year 3 and 6 reports in year 4 . Year 3 does have a larger number of comments per report but one individual feedback report was particularly rich in commentary. WTL-type comments outnumber LTW-type comments, with $58 \%$ and $62 \%$ WTL-type comments in year 3 and 4 , respectively.

'Figure 2(a) is never referred to in the text, figure 3 has the wrong caption and none of the frequency axes have units. It would be nice if the plots with multiple curves used dashed lines in addition to coloring in order to distinguish between curves.'

'The original theory and method part was slightly discontinuous, since the paragraphs written by different authors were not fully compatible with each other, and an effort were done to increase the readability'.

The comments exemplify how the students are beginning to internalise the standards of scientific writing and adaptation of presentation such writing entails.

As for the content-oriented WTL comments, two observations appear particularly important. First of all, there are comments in the material where students claim that their conversations in their feedback sessions enhanced their learning:

'In the end we had a valuable discussion regarding the general structure of a lab-report, which sections should be included, where focus should be, etc.'

A problem that has been observed in student writing in engineering is precisely this challenge of structure and selection $[64,65]$ and the students' discussions here seem to have helped generate more focused and effective laboratory reports. Arriving at such focus reflects the concomitant content understanding enabling effective selection.

A second and equally important observation in the content-oriented peer feedback is the critical reading that goes into it. Students need to assess the comments they receive and revise accordingly. One example is the comment from one pair of peers when they ask: 'it is a bit unclear if you have a transmission line modeled as a cavity or in what way the transmission line 'is' a cavity.' Here the authors respond that 'As we see it the transmission line is the cavity and together with ground and capacitor it represents a cavity resonator.' This exchange exemplifies a WTL content-oriented comment to us, since the two student pairs must first revisit the physics of the lab to articulate their question. Similarly, the authors too must re-read their text, the theory, and instructions to re-assess their text. In this case, revision was minimal and a second review round would have been called for in order to also refine the written articulation in the lab report and explore the LTW dimension of the comments.

There were a few comments that were valid but perhaps less urgent, and there were a few peer comments that were incorrect, for example:

'We got impression from your sentence that the purpose of sending microwave to cavity is to drive it. We think that you send microwave signal to the cavity in order to confine the photon in order to couple the photon to the qubit system, not to drive.' 
For the teachers and from the literature as well as the instructions, this comment suggests that the peer readers do not understand the Jaynes-Cummings model. Crucially, the authors did not change their lab report text in the way suggested:

'No change made here. The resonating cavity is driven by the incoming signal, just like a classic oscillator would be. Confining more photons in the cavity is exactly the same as causing the oscillator to oscillate with increasing amplitude, being driven harder. The qubit is coupled to the cavity, regardless of what microwave signal we apply.'

So, there is a risk with peer feedback - the blind leading the blind - but we see very little of that. Instead, it seems the increased critical reading activity and the closer attention to text have the opposite effect and make students question content issues in the lab reports in their discussions about and negotiations of feedback comments. As such this finding is in line with the literature on formative feedback [66] including findings from physics [38] and English as second or foreign language contexts. [67]

In combination, the peer review process and the use of more articulate communication of criteria (years 3 and 4) appear to have directed students' attention to the concepts we intended without our having to produce a guided review template. The process also seems to have enhanced learning as indicated by the grades and the peer commentary. Consequently, we believe that the number of content-oriented comments and their character, along with the revision they generated, exemplify how an effective peer response setup enables the type of learning from a lab report assignment that the students claimed it did in the work of Carter et al [31].

\section{Discussion and lessons learned}

As demonstrated above, a WTL activity including criterion-based student peer review can lead to enhanced understanding and reduced spread in performance in the student group (cf figure 1). When students write in pairs that the teacher has designed, they help enhance each other's understanding and writing. A similar mechanism seems to be at work during peer review where even the better of the first-version reports were improved in their second versions, which suggests that the more skilled students also benefitted from this practice. The revisions prompted by the teacher and peer feedback significantly improved the reports. An additional mechanism at work in the peer review process is that of learning from being a reviewer and not only from getting review comments [68-70]. Several students expressed that while teacher feedback was crucial, giving and receiving peer comments had also improved their own writing as well as their understanding. We believe that the distribution of peer comments in year 3 and year 4 can be interpreted as substantiating that student claim (cf figure 2).

We also focused the design on improving the articulation and communication of assessment criteria and rubrics. The progressively clearer communication of expectations for the lab reports is one contributing factor for the improved marks. However, the process of finetuning rubrics may have led to fluctuation in the assessment from year to year. To minimise that risk, our formulation of the $\mathrm{CHI}$ rubrics was aided by a thorough criterion-based reassessment of the previous set of reports, the original grading of which had been done using the same but less explicitly articulated criteria and without the systematic use of rubrics. This reassessment also highlighted some grading inconsistencies - more easily avoidable with the use of rubrics - but preserved, with few exceptions, the overall ranking of the reports within each of the student groups. From our course-specific perspective, the new rubrics facilitated high-quality and time-efficient grading of the year-4 reports.

However, it is difficult to identify which of the design changes of this lab and writing assignment led to which improvements. We are not alone in facing the difficulty of assessing which aspects of WTL best promote learning: it is likely that the effect on learning relies on 
synergies between the various components [9, 23, 32]. WTL tasks, like most teaching and learning activities, are equally susceptible to things like student motivation; student familiarity with the genres employed; student workload; and the problems of even devising an experimental setup in a structured manner.

Consequently, there are evident limitations to the quantitative and qualitative analyses of report quality, grades, and feedback comments in this attempt to document and share our assignment design. Given the fundamental limitation that our study is not a full-scale experimental research study [44], we still hope our account of the course context and action research conditions address the methodological limitations. Nevertheless, a confounding parameter regarding the improved course grades may be the natural variation in student preparation and student cohorts. Such cohort variation could conceivably have led to enhanced reports even in the absence of the changes to the lab exercise. Furthermore, the action research context results in a comparatively small number of students, yielding a relatively large uncertainty in the results for the respective years. Nonetheless, the results reported in figures 1 and 2 are quite encouraging.

Granted a small sample in our data, we still believe we have been able to isolate some of the factors that promote increased content learning and improved writing performance in the course. We are confident that the lab report task description, and the learning activities that follow, have distinguishable effects on the learning of quantum mechanics and not only on LTW lab reports in quantum mechanics. The critical components include: clear learning outcomes; deliberately articulated criteria developed specifically for lab reports, with the intention to facilitate formative assessment; using these criteria in collective feedback and peer feedback activities; and finally summative teacher feedback. We also believe that these components can be adjusted and used for similar writing assignments across disciplines and levels.

\section{Conclusion}

In conclusion, a WTL task connected to experimental work constitutes a useful course component at the master's level. The constructive alignment of well-defined aims, learning objectives, instruction, and formative assessment can clearly provide a meaningful learning experience. Student peer feedback can further enhance learning and lead to improved laboratory reports. The design described here satisfies our goals and seems transferable to other contexts and experiments [9]. As long as the teaching and learning activities are well prepared, a very demanding state-of-the-art lab experiment can be assigned to MSc students and give them a realistic sense of the research in the field. Such practice also appears to promote a sense of engagement with the writing and approaching the identity of a researcher [71]. However, given these students' backgrounds and limited experiences in reading the research literature, or of scientific/technical writing, further socialization into the discourse community may have to be supported by program learning outcomes. An isolated course module cannot meet such a learning outcome on its own. Instead, such socialization relies on that 'the teaching of writing and the teaching of science can find common ground in the idea of a laboratory' (Lerner [8], p 6).

\section{Ethical statement}

This research was carried out in accordance with the principles of IOP's ethical policy; no student participants are identifiable in our manuscript, and we will deidentify our source material upon request for access. 


\section{Acknowledgments}

We acknowledge funding for course development from the Chalmers Area of Advance Nanoscience and Nanotechnology and from the Knut and Alice Wallenberg Foundation through WACQT. We thank Andreas Eriksson and Michael Pemberton for constructive comments on early version of the manuscript. We would also like to thank the anonymous reviewers for their perceptive and constructive reading.

\section{ORCID iDs}

Jonas Bylander (iD https://orcid.org/0000-0003-4521-710X

Magnus Gustafsson (D) https://orcid.org/0000-0002-8614-638X

\section{References}

[1] Russell D R 2001 Where do the naturalistic studies of WAC/WID point? A research review WAC for the New Millennium: Strategies for Continuing Writing across the Curriculum Programs ed S H McLeod, E Miraglia, M Soven and C Thaiss (Urbana, Illinois: National Council of Teachers of English) pp 259-98

[2] Ivanic R and Lea M R 2006 New contexts, new challenges: the teaching of writing in UK higher education Teaching Academic Writing in UK Higher Education: Theories, Practices and Models ed L Ganobcsic-Williams (Houndmills and New York: Palgrave Macmillan) ch 1

[3] Young A 2006 Teaching Writing across the Curriculum 4th edn (Upper Saddle River, New Jersey: Pearson)

[4] Stephen F 1995 Becker guest comment: teaching writing to teach physics Am. J. Phys. 63587

[5] Mermin N D 2003 Writing physics Am. J. Phys. 71 296-301

[6] Kalman J and Kalman C 1996 Writing to learn Am. J. Phys. 64 954-5

[7] Franklin S V and Hermsen L M 2014 Real-time capture of student reasoning while writing Phys. Rev. Spec. Top. Phys. Educ. Res. 10020121

[8] Lerner N 1993 The Idea of a Writing Laboratory (Carbondale: Southern Illinois University Press)

[9] Paretti M, McNair L and Leydens J 2014 Engineering communication Cambridge Handbook of Engineering Education Research ed A Johri and B Olds (Cambridge: Cambridge University Press) pp 601-32

[10] Thaiss C, Reynolds J A, Katkin W and Thompson R J Jr 2012 Writing-to-learn in undergraduate science education: a community-based, conceptually driven approach CBE_Life Sci. Educ $\mathbf{1 1}$ $17-25$

[11] Hand B, Prain V, Keys C W and Collins S 1999 Using the science writing heuristic as a tool for learning from laboratory investigations in secondary science J. Res. Sci. Teach. 361065

[12] Hoehn J R and Lewandowski H J 2020 Framework of goals for writing in physics lab classes Phys. Rev. Phys. Educ. Res. 16010125

[13] Anna K and Etkina E 2007 Acting like a physicist: student approach study to experimental design Phys. Rev. Spec. Top. Phys. Educ. Res. 3020106

[14] Dunnet M N, Gorman K and Bartlett P A 2019 Assessing first-year undergraduate physics students' laboratory practices: seeking to encourage research behaviours Eur. J. Phys. $\mathbf{4 0} 015702$

[15] Funkhouser K, Martinez W M, Henderson R and Caballero M D 2019 Design, analysis, tools, and apprenticeship (data) lab Eur. J. Phys. 40065701

[16] Holmes N G and Wieman C E 2018 Introductory physics labs: we can do better Phys. Today 71 $38-45$

[17] Caballero M D, Dounas-Frazer D R, Lewandowski H J and MacKenzie S R 2018 Labs are necessary, and we need to invest in them APS News 27 5-8

[18] Wilcox B R and Lewandowski H J 2017 Developing skills versus reinforcing concepts in physics labs: insight from a survey of students' beliefs about experimental physics Phys. Rev. Phys. Educ. Res. 13010108 
[19] Smith E M, Stein M M, Walsh C and Holmes N G 2020 Direct measurement of the impact of teaching experimentation in physics labs Phys. Rev. X 10011029

[20] Donovan P 2014 Closing the feedback loop: physics undergraduates' use of feedback comments on laboratory coursework Assess. Eval. Higher Educ. 39 1017-29

[21] Kate Kiefer, Mike Palmquist, Nick Carbone, Michelle Cox and Dan Melzer (2000-2018) An Introduction to Writing Across the Curriculum. Fort Collins, CO: The WAC Clearinghouse. https:// wac.colostate.edu/resources/wac/intro/

[22] John M 1993 Ackerman the promise of writing to learn Written Commun. 10 334-70

[23] Demaree D 2006 Toward understanding writing to learn in physics: investigating student writing PhD Thesis Ohio State University

[24] Docktor J L and Mestre J P 2014 Synthesis of discipline-based education research in physics Phys. Rev. Spec. Top. Phys. Educ. Res. 10020119

[25] Foote K and Martino S 2018 Implementing investigative labs and writing intensive reports in large university physics courses Phys. Teach. 56 466-9

[26] Brigati J R and Swann J M 2015 Facilitating improvements in laboratory report writing skills with less grading: a laboratory report peer-review process J. Microbiol. Biol. Educ. 16 61-8

[27] Allie S, Buffler A, Kaunda L and Inglis M 1997 Writing-intensive physics laboratory reports: tasks and assessment Phys. Teach. 35 399-405

[28] Kiani L S and Menke C 2015 Refining scientific writing skills with feedback that works for students and instructors Education and Training in Optics and Photonics: ETOP Proc. SPIE 9793 $97932 \mathrm{~N}$

[29] Kane D M and Browne P G 2009 Laboratory report writing on optical physics undergraduate labs - draft and feedback processes to facilitate student learning \& skill development Conf. 11th Education and Training in Optics and Photonics Proc. SPIE $966696661 \mathrm{M}$

[30] Ellingsen P G and Støvneng J A 2018 Student laboratory reports: an approach to improving feedback and quality Eur. J. Phys. 39035701

[31] Carter M, Ferzli M and Wiebe E N 2007 Writing to learn by learning to write in the disciplines $J$. Bus. Tech. Commun. $21278-302$

[32] Bangert-Drowns R L, Hurley M M and Wilkinson B 2004 The effects of school-based writing-tolearn interventions on academic achievement: a meta-analysis Rev. Educ. Res. $\mathbf{7 4}$ 29-58

[33] Klein P D 2015 Mediators and moderators in individual and collaborative writing to learn J. Writing Res. 7 201-14

[34] Galbraith D 2015 Conditions for writing to learn J. Writing Res. 7 215-26

[35] Negretti R 2012 Metacognition in student academic writing Written Commun. 29 142-79

[36] Stanley J T and Lewandowski H J 2018 Recommendations for the use of notebooks in upper-division physics lab courses Am. J. Phys. 86 45-53

[37] Dounas-Frazer D R and Reinholz D L 2015 Attending to lifelong learning skills through guided reflection in a physics class Am. J. Phys. 83 881-91

[38] Lasry N, Charles E and Whittaker C 2016 Effective variations of peer instruction: the effects of peer discussions, committing to an answer, and reaching a consensus Am. J. Phys. 84 639-45

[39] Hattie J and Timperley H 2007 The power of feedback Rev. Educ. Res. 77 81-112

[40] Nicol D J 2009 Good designs for written feedback for students McKeachie's Teaching Tips: Strategies, Research, and Theory for College and University Teachers 13th edn ed M D Svinicki and W J McKeachie (Belmont: Wadsworth) ch 9 pp 108-23

[41] Boud D and Molloy E 2013 Rethinking models of feedback for learning: the challenge of design Assess. Eval. Higher Educ. 38 698-712

[42] Nicol D 2010 From monologue to dialogue: improving written feedback processes in mass higher education Assess. Eval. Higher Educ. 35 501-17

[43] Bennett R E 2011 Formative assessment: a critical review Assess. Educ.: Princ. Policy Pract. 18 $5-25$

[44] Harris K R and Graham S 2014 Conducting high quality writing intervention research: twelve recommendations J. Writing Res. 6 89-123

[45] Haswell R H 2005 NCTE/CCCC's recent war on scholarship Written Commun. 22 198-223

[46] Biggs J M and Tang C 2007 Teaching for Quality Learning at University 3rd edn (Milton Keynes: Open University Press)

[47] Galvez E J 2010 Qubit quantum mechanics with correlated-photon experiments Am. J. Phys. 78 $510-9$ 
[48] Lukishova S G 2017 Quantum optics and nano-optics teaching laboratory for the undergraduate curriculum: teaching quantum mechanics and nanophysics with photon counting instrumentation 14th Conf. on Education and Training in Optics and Photonics: ETOP Proc. SPIE 10452 104522I

[49] Yorke M 2003 Formative assessment in higher education: moves towards theory and the enhancement of pedagogic practice High. Educ. 45 477-501

[50] Nicol D J and Macfarlane-Dick D 2006 Formative assessment and self-regulated learning: a model and seven principles of good feedback practice Stud. High. Educ. 31 199-218

[51] Sampson V and Walker J P 2012 Argument-driven inquiry as a way to help undergraduate students write to learn by learning to write in chemistry Int. J. Sci. Educ. 34 1443-85

[52] Sanders N E, Kohler S, Faesi C, Villar A and Zevin M 2017 Incorporating current research into formal higher education settings using astrobites Am. J. Phys. 85 741-9

[53] Figueiredo A P S and Figueiredo N 2020 A quantitative analysis of the interaction among students in peer instruction classes Eur. J. Phys. 4112

[54] Zhang C-L, Hou Z-Y, Si Y-C, Wen X-Q and Tang L 2020 Application of peer instruction in the laboratory task of measuring the effective mass of a spring Eur. J. Phys. 38065705

[55] Koch J et al 2007 Charge-insensitive qubit design derived from the Cooper pair box Phys. Rev. A 76042319

[56] Schreier J A et al 2008 Suppressing charge noise decoherence in superconducting charge qubits Phys. Rev. B 77180502

[57] Bylander J 2017 Superconducting quantum bits of information-coherence and design improvements The Oxford Handbook of Small Superconductors 1st edn ed A V Narlikar (Oxford: Oxford University Press) pp 524-66

[58] 2011 Avdelningen för fackspråk och kommunikation 2017 Bedömning Av Den Skriftliga Presentationen Rapport av skriftlig rapport i kandidatarbete-HISS (Gothenburg: Chalmers University of Technology, Division for Language and Communication)

[59] Hyland K and Hyland F 2006 Feedback on second language students' writing Lang. Teach. 39 83-101

[60] Anderson P, Bergman B, Bradley L, Gustafsson M and Matzke A 2010 Peer reviewing across the atlantic: patterns and trends in L1 and L2 comments made in an asynchronous online collaborative learning exchange between technical communication students in Sweden and in the United States J. Bus. Tech. Commun. 24 296-322

[61] Gillespie P and Lerner N 2008 The Longman Guide to Peer Tutoring 2nd edn (London: Longmans Green)

[62] Hanrahan S J and Isaacs G 2001 Assessing self- and peer-assessment: the students' views Higher Educ. Res. Dev. 20 53-70

[63] Liu J and Sadler R W 2003 The effect and affect of peer review in electronic versus traditional modes on L2 writing J. Engl. Acad. Purposes 2 193-227

[64] Paretti M C, Eriksson A and Gustafsson M 2019 Faculty and student perceptions of the impacts of integrating content and language learning on students' development as engineers IEEE Trans. Profess. Commun. 62 27-42

[65] Eriksson A 2018 Redesigning a discipline-specific writing assignment to improve writing on an emi programme of engineering J. Acad. Writing 8 48-66

[66] Huisman B, Saab N, van den Broek P and van Driel J 2019 The impact of formative peer feedback on higher education students' academic writing: a meta-analysis Assess. Eval. Higher Educ. $\mathbf{4 4}$ $863-80$

[67] Zhu Q and Carless D 2018 Dialogue within peer feedback processes: clarification and negotiation of meaning Higher Educ. Res. Dev. 37 883-97

[68] Gunersel A B and Simpson N 2009 Improvement in writing and reviewing skills with calibrated peer review ${ }^{\mathrm{TM}}$ Int. J. Scholarship Teach. Learn. 3 2-14

[69] Cho Y H and Cho K 2011 Peer reviewers learn from giving comments Instrum. Sci. 39 629-43

[70] Huisman B, Saab N, van Driel J and van den Broek P 2018 Peer feedback on academic writing: undergraduate students' peer feedback role, peer feedback perceptions and essay performance Assess. Eval. Higher Educ. 43 955-68

[71] Poe M, Lerner N and Craig J 2010 Learning to Communicate in Science and Engineering: Case Studies from MIT (Cambridge, MA: MIT Press) 